COMMENT. The authors comment that these MRI findings may be specific to infantile neuoaxonal dystrophy and permit early diagnosis. The clinical picture includes upper and lower motor neuron deficits, including progressive weakness, difficulty in walking, hypotonia, muscle atrophy, hyperactive reflexes, Babinski signs, and optic atrophy. Diagnosis is confirmed by peripheral nerve biopsy, which shows globular swellings on the axons. Axonal swelling may also occur in Hallervorden-Spatz disease, Friedreich's ataxia, and other neurodegenerative diseases, however.

\title{
MRI IN INFANTILE KRABBE DISEASE
}

Serial MRI findings paralleling the clinical deterioration of a year-old child with Krabbe disease are reported from the University of Rochester Medical Center, New York. At 13 months, an abnormal high signal on $\mathrm{T}_{2}$ weighted images in the frontoparietal white matter and cerebellar white matter was correlated with severe developmental delay, increased tone, and hyperextension (stage 2). At 32 months, MRI changes had progressed to include central and cortical atrophy, decreased white matter volume, thalamic and caudate atrophy, and abnormal high signal in all motor tracts except the anterior limb of the internal capsule. Clinically, the child was in stage 3, with spasticity of the upper extremities, peripheral neuropathy, and no response to auditory or visual stimuli. (Farley TJ et al. Serial MRI and CT findings in infantile Krabbe disease. Pediatr Neurol Nov/Dec 1992; $\underline{8}$ : 455-458). (Correspondence: Dr Ketonen, Dept Radiology, University of Rochester Medical Center, Box 648, 601 Elmwood Ave, Rochester, NY 14642).

COMMENT. The 3-stages of Krabbe disease described by Hagberg begin with hyperirritability, restlessness, and frequent crying. Convulsions may develop, induced by sensory stimuli. Development becomes delayed, tone is increased, and later, reflexes are difficult to elicit and are absent in the lower limbs. Terminally, the infant is flaccid and blind. CSF protein is elevated and nerve conduction is delayed. The absence of the enzyme galactosyl ceramide B-galactosidase in leukocytes and skin fibroblasts is diagnostic, a test result common to all variants and stages of Krabbe disease, including antenatal.

\section{BIOCHEMICAL MARKER FOR MENKES DISEASE}

Plasma and CSF levels of catechols in 10 patients with Menkes disease, ranging in age from 9 days to 27 months, were compared with control groups and patients with congenital absence of dopamine-B-hydroxylase (DBH) at the National Institutes of Health, Bethesda, MD. The neurochemical pattern in Menkes disease patients was characterized by high dihydroxyphenylalanine (DOPA), dopamine (DA), and dihydroxyphenylacetic acid (DOPAC) levels, 